\title{
Las implicancias del Brexit en Europa y en el mundo ${ }^{1}$
}

\section{Brexit implications in Europe and around the world}

\section{Norberto Consani ${ }^{2}$ y Juan Carlos Pérsico ${ }^{3}$}

Resumen: se analiza la trascendencia del Brexit, que significa la salida por propia voluntad de Gran Bretaña del bloque regional, y los múltiples efectos no sólo en este país sino también en la Unión Europea en su conjunto y en el mundo, además de los grandes desafíos que afectan su composición territorial actual, sus partidos políticos tradicionales, su economía y comercio, y el bienestar general de sus ciudadanos, en una sociedad que ha quedado profundamente dividida.

Del mismo modo, también se observa cómo el proceso afectaría a la Unión Europea por perder a la quinta economía mundial (y segunda en el bloque regional) y a una de las principales potencias militares del planeta, y la preocupación por contener el efecto contagio del Brexit en sus países miembro, en los que se observa con gran preocupación el crecimiento constante de movimientos políticos nacionalistas populistas contrarios al proceso de integración regional europeo.

Palabras clave: gran Bretaña, Brexit, Europa, mundo, implicancias.

Abstract: this paper analyzes Great Britain's exit from the EU, which implies the country's own will to leave the regional block, as well as the multiple effects that this has not only on this country but also in the European Union as a whole, as well as around the world. We also look at the great many challenges affecting its current territory, its traditional political parties, its economy and trade, and the citizens' general wellbeing, in a society that is sharply divided.

Moreover, this paper looks at how this process might affect the European Union with the loss of the fifth most important world economy (and the second within the region) and one of the main military powers on the planet, as well as at the concern to contain the contagious effect that Brexit may have on the member states, where considerable worry is arousing about the constant growth of populist nationalist political movements which are against the European regional integration process.

Key words: great Britain, Brexit, Europe, world, implications.

Doi: https://doi.org/10.24215/23142766e080

${ }^{1}$ Recibido el 25/11/2019. Aceptado el 01/12/2019

2 Profesor Titular de Derecho Internacional y Relaciones internacionales en grado y posgrado (Maestria y Doctorado) y Director del IRI

${ }^{3}$ Docente de Derecho Internacional Público en la Facultad de Ciencias Jurídicas y Sociales de la Universidad Nacional de La Plata (UNLP) y en la Facultad de Derecho y Ciencias Políticas de la Universidad Católica de La Plata (UCALP). Coordinador del Departamento de Europa del Instituto de Relaciones Internacionales (IRI) de la Universidad Nacional de La Plata (UNLP). Secretario de la Cátedra Libre "Estudios de la Unión Europea" de la Universidad Nacional de La Plata (UNLP). E-mail: persico@fibertel.com.ar 


\section{Introducción: el camino hacia el Brexit}

El Primer Ministro británico David Cameron a principios del año 2013 anunció que, si ganaba las elecciones generales del año 2015 , se comprometía a realizar una consulta popular sobre la permanencia o no del Reino Unido como Estado miembro de la Unión Europea. Dicha jugada política fue en respuesta a las presiones ejercidas por los sectores más conservadores de su propio partido y para detener el importante crecimiento de UKIP (Partido de la Independencia del Reino Unido) liderado por Nigel Farage.

En el Consejo Europeo celebrado en el mes de febrero de 2016, David Cameron, a cambio de hacer campaña por la permanencia de su país en la Unión, obtuvo para Gran Bretaña importantes concesiones en materia de gobernanza económica, competitividad, soberanía, prestaciones sociales y libre circulación de parte de los Jefes de Estado y de Gobierno del resto de los países miembros del bloque regional, al adoptarse la "Decisión relativa al nuevo régimen del Reino Unido en la Unión Europea", con la aclaración de que ella sólo se haría efectiva si el pueblo británico decidía que su país siga integrando la Unión.

El 23 de junio de 2016 se llevó a cabo el referéndum en Gran Bretaña, en el que se impuso la opción que propiciaba salir del bloque regional por el 51,9\% de los votos; por su parte, la alternativa a favor de la permanencia cosechó el $48,1 \%$ de las preferencias. La participación se situó en el $72 \%$ de los 46,5 millones de ciudadanos habilitados para votar. A las pocas horas de ser conocido dicho resultado, el Primer Ministro británico, David Cameron, renunció a su cargo y expresó que dejará a su sucesor la responsabilidad de iniciar el proceso de separación con Europa.

Es decir, se impuso el "Brexit"4, lo que provocó un tremendo impacto político en el viejo continente y también a nivel mundial, ya que era la primera vez que un país decidía separase de la Unión Europea, e indudablemente dicha decisión tendrá consecuencias profundas y aún desconocidas para el futuro no sólo de los británicos sino también para el resto de Europa 5 .

Las razones por las que se impuso el Brexit hay que buscarlas en el desencanto y la frustración de un amplio sector de la sociedad británica que sostiene que el crecimiento económico del Reino Unido se encuentra frenado por la Unión Europea, la que le impone muchas reglamentaciones y trabas burocráticas para poder realizar negocios, y que considera a la vez que aportan mucho dinero al bloque regional para recibir muy poco a cambio. Otros de los motivos es que quieren que su país recupere el control absoluto de sus fronteras y que se reduzca el número de migrantes que llegan a trabajar, lo que se opone claramente a uno de los principios más importantes de la Unión, que es la "libertad de circulacion", y resalta que otro peligro adicional que trae la inmigración es el ingreso de terroristas. Además, reclaman más soberanía ya que rechazan la idea de "una Unión más estrecha" y cualquier intento de convertir al bloque en los “Estados Unidos de Europa”̋.

\footnotetext{
${ }^{4}$ Acrónimo en inglés formado por la unión de las palabras Britain -Gran Bretaña- y exit -salida-.

${ }^{5}$ Para algunos analistas internacionales es el acontecimiento geopolítico más importante que vivió Europa desde la segunda guerra mundial, junto con la caída del Muro de Berlín.

${ }^{6}$ En definitiva los partidarios del Brexit expresan una vieja e histórica posición británica: la "insularidad" frente al "continente".
} 
A menos de tres semanas del referéndum británico, el 13 de julio de 2016, se consumó la salida anticipada del poder de David Cameron y asumió como Primer Ministro del Reino Unido la conservadora Theresa May, quien se convirtió de este modo en la segunda mujer en la historia de Gran Bretaña ${ }^{7}$ en desempeñar dicho cargo. May ocupaba el cargo de Ministra del Interior en el gabinete de Cameron e hizo campaña a favor de permanecer en la Unión Europea. A pesar de ello, y como su tarea principal ha sido liderar la compleja salida británica de la Unión, inicialmente nombró a prominentes partidarios del Brexit en puestos clave dentro de su gobierno ${ }^{8}$.

El 13 de marzo de 2017 las dos Cámaras del Parlamento británico aprobaron la ley ${ }^{9}$ que permitía a la Primera Ministra iniciar el proceso de desconexión del Reino Unido de la Unión Europea, sin ninguna condición previa, ya que se suprimieron dos enmiendas a dicha norma que exigían al gobierno asegurar los derechos de los ciudadanos comunitarios y facultar al Parlamento a votar sobre el futuro acuerdo de salida de la Unión, ello a pedido de Theresa May, quien sostuvo que adquirir tales compromisos por ley le quitaba margen de acción en las negociaciones con el bloque regional. Pocos días después, el 16 de marzo la Reina Isabel II, en su carácter de Jefa de Estado, rubricó la aludida ley que permitió al gobierno poner en marcha la salida de Gran Bretaña de la Unión Europea.

En consecuencia, el 29 de marzo de 2017 el gobierno británico activó formalmente el proceso para que el Reino Unido se retire del bloque regional europeo invocando el artículo 50 del Tratado de Lisboa ${ }^{10}$. De este modo, se dió comienzo a un período de tensas, complejas y duras negociaciones entre Gran Bretaña y sus ex socios de la Unión Europea, que pueden terminar con un acuerdo que redefina las relaciones entre ambas partes o sin consenso alguno, lo que generará múltiples complicaciones, especialmente para Londres.

Con motivo del Brexit se aplicó por primera vez el artículo 50 del Tratado de la Unión Europea (que entrara en vigor el 1ㅇ de diciembre de 2009), que prevé el retiro de un Estado miembro de la Unión Europea. El Estado que decide retirarse, de conformidad con sus normas constitucionales del bloque regional, debe notificar su intención al Consejo Europeo. Teniendo en cuenta las orientaciones del mencionado órgano, la Unión Europea debe negociar y celebrar con dicho Estado un acuerdo que establezca la forma y condiciones de su retiro, el cual debe ser aprobado por el Consejo de la Unión por mayoría cualificada, ello previa aprobación del Parlamento Europeo. A partir de la fecha de entrada en vigor del acuerdo de referencia, los tratados europeos dejarán de aplicarse al Estado en cuestión, o en su defecto, a los dos años de la notificación que hubiere hecho el Estado al Consejo Europeo, salvo que este órgano, con la conformidad del Estado involucrado, decida por unanimidad prorrogar dicho plazo. El Estado que quiere retirarse no participa ni de las delibera-

\footnotetext{
${ }^{7}$ La primera fue Margaret Thatcher entre los años 1979 y 1990.

${ }^{8}$ Como Ministro de Finanzas designó a Philip Hammond, como Ministro de Relaciones Exteriores al ex alcalde de Londres, Boris Johnson, y a cargo de la Secretaría de Estado para abandonar la Unión Europea a David Davis.

${ }^{9}$ El proyecto de dicha norma debió ser tratado con urgencia, luego que el Tribunal Supremo de Londres resolviera que la Primera Ministra necesitaba el permiso del Parlamento para activar el artículo 50 del Tratado de Lisboa

${ }^{10}$ La carta firmada por la Primera Ministra Theresa May fue entregada en mano por su enviado Tim Barrow al Presidente del Consejo Europeo Donald Tusk.
} 
ciones ni de las decisiones que adopten al respecto tanto el Consejo Europeo como el Consejo de la Unión. Asimismo, el Estado miembro que se ha retirado puede solicitar en el futuro una nueva adhesión al bloque regional.

De este modo, los británicos debieron comenzar complicadas y arduas negociaciones con la Unión Europea en las que se debe acordar cómo será el retiro de Gran Bretaña y a la vez su nueva relación con el bloque regional. Sin duda, después de la amarga experiencia vivida con los británicos, la Unión tiene sólidos fundamentos para imponer un acuerdo que consiga desalentar a otros países miembros a abandonarla ${ }^{11}$.

Cabe asimismo recordar que el 8 de junio de 2017 tuvieron lugar en el Reino Unido las elecciones generales anticipadas, convocadas en el mes de abril por la Primera Ministra Theresa May, con la intención de fortalecer su posición ante las negociaciones que tenía que desarrollar con la Unión Europea por la salida de Gran Bretaña del bloque regional ${ }^{12}$.

El resultado de dichos comicios arrojó como ganador al partido de la Primera Ministra May, que obtuvo 318 escaños en la Cámara de los Comunes. Un triunfo con sabor agridulce, ya que los conservadores perdieron doce lugares que tenían en el momento del llamado a la nueva elección y, por ende, perdieron la mayoría absoluta que ostentaban. Eso significó que la Primera Ministra no pudiera gobernar en solitario, como lo estaba haciendo hasta entonces, sino que necesitó negociar con otros partidos para formar una coalición y obtener de ese modo 8 bancas más, lo que le permitiría conseguir la mayoría absoluta con el apoyo de 326 representantes, en una Cámara compuesta por un total de 650 bancas. En tal sentido, el partido Unionista Democrático de Irlanda del Norte (DUP), que logró 10 escaños, apoyó en el Parlamento a los conservadores para formar el nuevo gobierno.

Estos resultados situaron a la Primera Ministra May en una posición difícil, ya que había convocado a elecciones tres años antes de lo previsto, confiada en que podría ampliar aún más la mayoría absoluta que ostentaba y, de esa manera, contar con un mandato robustecido para afrontar con la Unión Europea las negociaciones por el Brexit.

\section{Las implicancias del Brexit}

Ciertamente el Brexit producirá múltiples efectos negativos, principalmente para el Reino Unido, pero también para la Unión Europea, y afectará no sólo la unidad y bienestar de Gran Bretaña sino además la imagen que proyecta Europa en el mundo. Al respecto, se pueden señalar una serie de cuestiones en las que dicha salida repercutirá indudablemente con mucha importancia.

\section{Escocia:}

El Brexit amenaza con precipitar un efecto dominó en el Reino Unido. La líder del Partido Nacionalista Escocés (SNP), Nicola Sturgeon, anunció que pedirá la realización de un

\footnotetext{
${ }^{11}$ Al respecto, el Presidente de la Comisión Europea, Jean-Claude Juncker, oportunamente expresó que Gran Bretaña será un tercer Estado que no tendrá el camino allanado para retirarse de la Unión.

12 La corta campaña se llevó a cabo en un clima enrarecido, ya que debió ser interrumpida en dos ocasiones debido a los atentados terroristas acaecidos en el estadio de Manchester, donde murieron 22 personas, y en el puente de Londres y el mercado de Borough, donde otras 10 personas perdieron su vida.
} 
segundo referéndum sobre la independencia de Escocia, porque sus connacionales ven su futuro como parte del bloque regional europeo. Del mismo modo, recordó que en el referéndum de septiembre de 2014 perdió la alternativa de la independencia, porque los unionistas lograron convencer a los escoceses que dejar Gran Bretaña significaría que Escocia se quedara fuera de la Unión Europea y aseguró que tomará todas las medidas necesarias para que su país se mantenga dentro de la Unión ${ }^{13}$. Cabe mencionar al respecto que el $62 \%$ de los escoceses votaron a favor de permanecer en el bloque regional, en tanto que el $38 \%$ lo hizo por la salida. Una eventual escisión de Escocia representaría un fuerte revés para Gran Bretaña, ya que representa el $8 \%$ de su PBI, sumado a ello que seguramente en tal caso abandonará la libra para adherir al euro. Así también, cabe señalar que el petróleo de Mar del Norte se encuentra en Escocia ${ }^{14}$, la que además cuenta con el $60 \%$ de la pesca británica.

Con respecto al nuevo referéndum sobre la independencia de Escocia, que por motivo del Brexit planea realizar el gobierno escocés para que su país siga perteneciendo a la Unión Europea, la Primera Ministra May expresó que rechazará su realización hasta tanto no finalicen las negociaciones para la salida del Reino Unido de la Unión. Asimismo, la Primera Ministra de Escocia ha requerido que el aludido referéndum escocés sea aprobado por ambas Cámaras del Parlamento británico para que tenga carácter de legalmente vinculante.

\section{Irlanda del norte - República de Irlanda:}

Una situación similar se presenta en el Ulster (Irlanda del Norte) ${ }^{15}$, donde también triunfó el voto a favor de la permanencia (56 \%) contra la salida (44\%). Poco después de conocerse el resultado, el partido nacionalista Sinn Fein de Irlanda reclamó que se efectúe un referéndum sobre la unificación de toda la isla.

La cuestión de la frontera entre Irlanda del Norte y la República de Irlanda sigue siendo un tema muy espinoso, ya que Dublín aseguró que vetaría el avance de las negociaciones si no obtenía garantías de que no habrá una "frontera física" entre ambas partes de la isla, lo que obligó a los negociadores a diseñar una fórmula a medida para tratar de solucionar el problema ${ }^{16}$.

En Irlanda se puede acabar la paz, ya que el Brexit reavivaría el conflicto que entre 1968 y 1998 provocó en Irlanda del Norte una gran violencia entre guerrillas, paramilitares y las fuerzas de seguridad. Los católicos luchaban por convertir a Irlanda del Norte en parte de la República de Irlanda, los protestantes por mantenerla dentro del Reino Unido. Con el acuerdo de 1998, Irlanda del Norte siguió siendo británica, pero se borró a todos los efectos la frontera que la separaba con la República de Irlanda, sin aduana ni vigilancia. Con el Brexit volverán las visas y controles. Esto recreará la situación que derivó en aquel conflicto.

\footnotetext{
${ }^{13}$ En la aludida ocasión en "No" obtuvo el 55, 3\% de los votos imponiéndose al "Si" que cosechó 44,7 de las preferencias.

${ }^{14}$ Se calcula que Escocia cuenta con reservas petroleras para más de veinte años.

${ }^{15}$ Cuenta con 1,8 millones de habitantes, representando el 3 \% de la población total del Reino Unido.

${ }^{16}$ Caso contrario, se deberían establecer controles en una frontera de 499 kilómetros, acabando con la libre circulación que ha existido en la totalidad de isla desde hace 20 años.
} 
Por los Acuerdos de Viernes Santo del año 1998, el Reino Unido está obligado a realizar un referéndum sobre la reunificación de Irlanda, ello si hay evidencias que confirmen un cambio en la opinión pública sobre su estatus constitucional ${ }^{17}$.

La Unión Europea planteó la necesidad de establecer un mecanismo de protección (o backstop) para impedir la aparición de una frontera física en las dos Irlandas, que hiciera resurgir la división y la violencia. ${ }^{18}$ La aludida fórmula establece que, mientras no se encuentre una solución mejor, el Reino Unido y la Unión Europea compartirán un territorio aduanero único para evitar aranceles, cuotas y controles entre los productos que circulen entre la República de Irlanda e Irlanda del Norte. Además, algunos temen que éste sea el comienzo de una separación entre Irlanda del Norte y el resto del Reino Unido. Por su parte, la Unión Europea ha asegurado que el "backstop" es de carácter temporal y excepcional, y sólo entrará en vigor si al final del período transitorio de salida (que expiraría en diciembre del año 2020, con posibilidad de prórroga de uno o dos años) no se ha logrado un acuerdo comercial entre ambas partes ${ }^{19}$.

\section{División de la sociedad y partidos políticos británicos:}

Asimismo, dado lo ajustado del resultado que arrojó el Brexit (51,9 \% contra el 48,1 $\%)$, se puso en evidencia la profunda división que existe sobre este tema entre los ciudadanos británicos: más de dos millones de ellos han suscripto una petición oficial dirigida al Parlamento del Reino Unido para que el país vuelva a celebrar otro referéndum sobre su permanencia o salida de la Unión Europea. Los firmantes exigen que se realice una segunda consulta considerando que la participación ha estado por debajo del $75 \%$ del padrón y que no se llegó a un mínimo del $60 \%$ de los votantes que se manifestaran en contra o favor del Brexit. Al respecto, varios líderes políticos británicos habían dicho que era imposible llevar a cabo un segundo referéndum.

Además se debe considerar que en Londres se impuso la opción de permanencia en la Unión Europea por el 75,2 \% de los votos. El alcalde de dicha ciudad, el laborista Sadiq Khan, al conocerse el resultado nacional del referéndum emitió un mensaje de tranquilidad al casi millón de ciudadanos europeos residentes en la capital del Reino Unido al decirles que son muy bienvenidos y que la ciudad les agradece la enorme contribución que le hacen, resaltando que ello no cambiará en el futuro. Asimismo, 148.000 londinenses firmaron una petición para solicitar al alcalde que declare a la ciudad de Londres independiente del Reino Unido de modo que continúe dentro de la Unión Europea.

Actualmente la población de Gran Bretaña se encuentra dividida en dos mitades casi iguales entre los brexiters (quienes se quieren ir de la Unión Europea) y los remainers (quienes se quieren quedar). Ambas partes están cada vez más radicalizadas, lo que dificulta cualquier posición común dentro del país. Lo mismo ocurre en el Parlamento británico: se encuentra dividido hasta tal punto que lo único que sabe es que no quiere que el país se vaya

\footnotetext{
${ }^{17}$ El territorio irlandés se partió en el año 1921 y la provincia del Ulster pasó a pertenecer al Reino Unido como Irlanda del Norte.

${ }^{18}$ Actualmente éste es el principal impedimento para que los legisladores británicos aprueben el Acuerdo de retirada negociado por Theresa May con la Unión Europea.

${ }^{19}$ Cabe recordar que Dublín tiene el derecho de veto sobre el acuerdo de salida de Gran Bretaña de la Unión Europea si se optase por alguna fórmula menos garantista.
} 
de la Unión Europea sin acuerdo, pero no es capaz de obtener una mayoría sobre lo que quiere, lo que trae como consecuencia que no se logre alcanzar al menos una alternativa que cuente con la mayoría suficiente para ser aprobada. También los dos grandes partidos, conservadores y laboristas, se encuentran internamente desunidos y, por tanto, sin posiciones unificadas. Lo mismo pasa con el gobierno de Theresa May: los ministros votan cosas distintas según sus preferencias, haciendo añicos la disciplina y colegialidad del Gabinete.

\section{Consecuencias económicas en Gran Bretaña:}

Comercio: Actualmente, el $45 \%$ de las exportaciones británicas se dirigen hacia la Unión Europea. Será para Gran Bretaña muy difícil compensar la pérdida del mercado europeo, ya que sin bien se esperaba un importante acuerdo comercial con Estados Unidos, el Presidente Trump ha dicho: "Si ellos no llegan a un acuerdo, no serán aptos para comerciar con nosotros". Además, la incertidumbre que genera el Brexit hará difícil a los británicos encontrar en el corto plazo grandes socios comerciales. A raíz del Brexit, el Reino Unido deberá reconstruir toda su red de acuerdos comerciales que tiene actualmente por ser miembro de la Unión Europea con diversos países.

La Libra Esterlina: Poco después de conocerse la noticia del Brexit cayó la cotización de la libra esterlina (dicha divisa ha retrocedido un $14 \%$ respecto del dólar y un 12 \% con relación al euro), ello produce también que se disparen los precios internos de la economía del Reino Unido y que los británicos tengan un menor poder adquisitivo.

Fuerza Laboral: Otro problema que se le presentará es la previsible merma en la entrada de trabajadores inmigrantes tras la salida del Reino Unido de la Unión Europea, lo que, según los especialistas, afectará la economía británica por la pérdida de ingresos fiscales (calculan unos 6.000 millones de libras anuales) ${ }^{20}$.

Economía británica: Asimismo, se prevé un aislamiento y reducción de la economía, la que según el Banco de Inglaterra se reduciría el $8 \%$ en un año luego de que el país salga de la Unión Europea. La economía británica en el año 2018 redujo su crecimiento a un 1,4 \%, su ritmo más bajo desde el año 2012, afectada por la incertidumbre que genera el Brexit. Las calificadoras internacionales Standard\&Poor y Fitch Group, con motivo del Brexit, bajaron la nota de la economía británica de triple $\mathrm{A}$ (que significa una máxima solvencia) a doble A por los efectos negativos que traerá aparejado dicho suceso.

Incremento del costo de vida en Gran Bretaña: los alimentos aumentarán de precio y la importación de componentes elevarán los costos industriales. En consecuencia, se deberá contener la inflación ${ }^{21}$.

Inversiones y acceso al crédito internacional: Se producirá una caída de las inversiones, ya que hasta ahora invertir en el Reino Unido era invertir allí y en los otros 27 miembros de la Unión, entre ellos Alemania y Francia. El financiamiento será difícil y caro, porque el Reino Unido debe tres veces más de lo que produce. Por ello, el mercado financiero internacional le restringirá el acceso al crédito y le impondrá intereses más altos.

\footnotetext{
${ }^{20}$ El Reino Unido requiere un flujo migratorio de 200.000 personas al año para sostener su economía, ello debido a la falta de mano de obra en algunas zonas, el envejecimiento de su población y su baja productividad.

${ }^{21}$ La inflación acumulada en el año 2017 fue del 1,4\%, siendo el valor máximo desde el año 2013.
} 
Bancos y City de Londres: Los bancos con sede en el Reino Unido se están preparando para enfrentar la situación post Brexit y varios de ellos están listos para emigrar al continente. Asimismo, Londres perderá su importancia como centro financiero, hoy día es el segundo luego de Nueva York a nivel mundial.

Empresas transnacionales y organismos europeos: Las aerolíneas británicas no podrán abrir nuevas rutas al continente. Airbus dejará de fabricar en Inglaterra, donde emplea a 14.000 personas. La Agencia Europea de Medicamentos, que es la encargada de evaluar, autorizar y vigilar los medicamentos de toda la Unión Europea, se irá a Amsterdam. También se retirará la Agencia Bancaria Europea. Incluso, numerosas empresas transnacionales radicadas en Gran Bretaña consideran mudarse a otro país de la Unión.

\section{Defensa Europea:}

El Brexit indudablemente significa un duro golpe para Europa, ya que perderá al quinto inversor mundial en gastos de defensa. Por cierto, la nueva Unión Europea sin Gran Bretaña será más débil en términos militares y perderá credibilidad en temas de defensa, ello debido al prestigio y capacidad de influencia del Reino Unido en el mundo.

A pesar de la visión británica proclive a proteger los intereses estratégicos de los Estados Unidos, las aportaciones del Reino Unido en materia de política exterior y defensa son muy importantes para la Unión Europea, considerando su capacidad de análisis, planificación, recursos militares y aportes a acciones concretas. La presencia y fuerza disuasoria de Gran Bretaña es importante para todo el bloque europeo.

Con motivo del Brexit, la Unión Europea perderá a una potencia nuclear y miembro permanente del Consejo de Seguridad de la ONU y, además, uno de los ejércitos de Estados miembro con mayor poder de despliegue en el exterior y mejores capacidades militares disponibles.

\section{Efecto contagio en el continente europeo:}

Por su parte, los líderes del resto de los Estados miembro del bloque regional y las instituciones comunitarias aspiran a que el divorcio con los británicos se produzca lo más rápido posible para neutralizar sus efectos negativos, para iniciar el rediseño de la Unión Europea y, a la vez, para evitar que dicha experiencia provoque reacciones en cadena en otros países integrantes de la Unión, sobre todo en Europa del Este.

Sin duda, el Brexit fue muy bien recibido por los partidos de extrema derecha, nacionalistas, euroescépticos y eurofóbicos del viejo continente. No bien fue conocida la noticia del triunfo del "Brexit", la francesa Marine Le Pen, líder del ultraderechista Frente Nacional, y Geert Wilders, del partido de la Libertad de Holanda, anunciaron que reclamarán la convocatoria de consultas populares en sus respectivos países para que los ciudadanos decidan si quieren o no continuar en la Unión. También se sumaron al reclamo los xenófobos del partido Alternativa para Alemania, el ultraderechista Partido del Pueblo de Eslovaquia y las fuerzas de la derecha nacionalista en Dinamarca, Suecia y Austria; en tanto que en Italia, el ascendente Movimiento Cinco Estrellas reafirmó sus críticas al rumbo europeo y su rechazo a la continuidad en el euro, a su vez que la derechista Liga del Norte vigorizó su exigencia de realización de un referéndum para salir de la Unión.

El desafío al status quo también se afianza en los países de Europa del Este de reciente incorporación al bloque regional, como Polonia, República Checa, Eslovaquia y 
Hungría, donde gobiernos nacionalistas promueven una reforma de los tratados europeos que les permita recuperar parte de la soberanía cedida a Bruselas, en especial en la materia migratoria.

El Brexit podría producir un efecto dominó que podría afectar gravemente todo el bloque regional si se extendiera en sus países miembro el populismo nacionalista, lo que provocaría inestabilidad e inseguridad en toda Europa e implicaría a la vez un grave riesgo político que podría llevar al futuro desmantelamiento de la Unión Europea.

\section{Gibraltar:}

En Gibraltar, el voto a favor de la permanencia en la Unión Europea se impuso por la abrumadora diferencia del $96 \%$, ello sin duda demuestra la gran importancia que tiene para los gibralteños mantener sin cambios la actual relación con España y el bloque regional europeo.

Al salir el Reino Unido de la Unión Europea, se restablecerán las facultades reconocidas por el Tratado de Utrecht a España; es decir, podrá cerrar o abrir la frontera terrestre a discreción ${ }^{22}$.

Pero además se debe considerar que la cuestión del Peñón de Gibraltar se despertará nuevamente en todos sus frentes: el colonial, territorial, marítimo y aéreo, ya que habrá cesado la anestesia que se aplicara durante muchos años sobre el conflicto debido a la común pertenencia de las partes (España y Gran Bretaña) al mismo bloque de integración regional.

Prueba de ello es que el 4 de abril de 2019, el Parlamento Europeo y el Consejo al aprobar un Reglamento sobre exención de visados se refirieron a Gibraltar como "una colonia de la Corona Británica" ${ }^{23}$ por primera vez en una norma comunitaria ${ }^{24}$. Ello es un anticipo de lo que le esperará de parte de la Unión Europea al Reino Unido una vez que se haya consumado el Brexit.

Cuando se consume la salida del Reino Unido de la Unión Europea, se suscribirá entre las partes un "Protocolo Específico" para aplicar a Gibraltar en el que se incluirán acuerdos con España sobre la cooperación fiscal, policial, aduanera y medioambiental, sobre los derechos de los ciudadanos (alrededor de 10.000 españoles trabajan en el Peñón) y sobre la lucha contra el contrabando (especialmente de tabaco).

\section{Malvinas:}

En las islas Malvinas el Brexit causa gran inquietud y temores a los kelpers por un doble motivo: una futura eventual situación económica adversa para Gran Bretaña podría quitarles o disminuir el apoyo financiero y militar que reciben, $y$, por otra parte, al no pertenecer más el Reino Unido a la Unión Europea, otros países del bloque regional, como ser España, Italia y Francia, que tienen históricamente buenas relaciones con Argentina, probablemente

\footnotetext{
22 No obstante, el cierre total no sería aconsejable por razones políticas, económicas, humanas, por lo que el paso debe estar abierto en las condiciones que España establezca.

${ }^{23}$ Actualmente el Reino Unido se refiere a Gibraltar como "territorio británico de ultramar" generándole rechazo la palabra "colonia" que es impulsada por España para reclamar la cosoberanía sobre el Peñón.

${ }^{24}$ Ello es sin lugar a dudas un importante apoyo de sus socios del bloque regional a la posición y reivindicaciones de España sobre el territorio de Gibraltar, los que han abandonado su posición neutral en este conflicto inclinándose por la postura española.
} 
dejen de apoyar en los organismos y foros internacionales la posición británica en cuanto a sus derechos soberanos sobre el archipiélago situado en el Atlántico Sur.

Además, al retirarse el Reino Unido del bloque regional europeo, perderían el libre acceso a su principal mercado de exportación de productos pesqueros, que es la Unión Europea $^{25}$.

\section{Desaceleración de la economía y comercio mundial:}

A principios de abril de este año, la Directora Gerente del Fondo Monetario Internacional (FMI) Christine Lagarde advirtió sobre el momento delicado, la vulnerabilidad y la incertidumbre que rodea a la economía mundial debido a las tensiones comerciales entre China y Estados Unidos y la intranquilidad en los mercados financieros por las dudas que genera el Brexit. Ambos sucesos provocaron la desaceleración de la economía global, la que crecerá por debajo del índice $(3,5 \%)$ que el organismo financiero internacional había estimado para el año 2019.

Por su parte, el Director General de la Organización Mundial de Comercio (OMC) Roberto Azevedo señaló que, debido al conflicto arancelario China y Estados Unidos y la situación que afecta a Europa debido al Brexit, el comercio global sólo crecerá un 2,6\% interanual en el año 2019, es decir, cuatro décimas menos que en el año anterior.

\section{Ultimos sucesos: el laberinto del Brexit}

El Parlamento británico el 14 de marzo de 2019 aprobó solicitar a la Unión Europea una prórroga del plazo para que opere la salida del Reino Unido del bloque regional (prevista inicialmente para el 29 de marzo) hasta el 30 de junio de 2019. Dicha petición fue tratada en el Consejo Europeo celebrado el 21 y 22 de marzo de 2019, el que fijó el día 12 de abril de 2019 para que Londres tome una decisión sobre lo que quiere hacer (incluyéndose también la posibilidad de permanecer en el bloque regional) y estableció a la vez que, si el Parlamento votaba afirmativamente en los próximos días el acuerdo de retirada negociado por May con la Union Europea, la fecha definitiva del Brexit sería el 22 de mayo de 2019.

Ante la falta de consenso sobre el Brexit, el 3 de abril el Parlamento votó un texto impulsado por conservadores y laboristas que obligaba a Theresa May a solicitar a la Unión Europea más tiempo para que el Reino Unido abandone el bloque regional e imponía la prohibición de que bajo ninguna circunstancia el país pudiera abandonar las instituciones comunitarias sin llegar a un acuerdo.

Por tal motivo, la Primera Ministra británica solicitó, a través de una carta dirigida al Presidente del Consejo Europeo, otra prórroga para que opere la salida del Reino Unido del

\footnotetext{
${ }^{25}$ Aproximadamente el $60 \%$ de los ingresos de las Islas Malvinas provienen de la exportación de productos pesqueros a la Unión Europea, representando ellos más de 100 millones de dólares por año.
} 
bloque regional ${ }^{26}$. Por su parte, la Unión Europea dejó asentado que cualquier nueva prórroga obligaría a los británicos a participar en las elecciones del Parlamento Europeo ${ }^{27}$ y designar a sus nuevos eurodiputados casi tres años después del referéndum de 2016 en que se impusiera el Brexit.

En consecuencia, el 10 de abril de 2019 el Consejo Europeo ${ }^{28}$ concedió al Reino Unido un nuevo plazo para concretar su salida, para lo que se fijó como fecha límite el 31 de octubre, pero se establecieron ciertos condicionamientos: la Unión Europea pondría en práctica un marco informal de funcionamiento a todos los niveles entre los veintisiete socios, quienes negociarían y pactarían sin la presencia de Gran Bretaña; dicho país se comprometía, en el transcurso de la nueva prórroga, a cooperar con lealtad con el bloque regional; y, si los británicos seguían siendo miembros de la Unión al 23 de mayo, estaban obligados a realizar las elecciones para el Parlamento Europeo, caso contrario salían de inmediato de ésta el 10 de junio.

El 22 de mayo de 2019, Theresa May efectuó su último intento de sacar al Reino Unido de la Unión Europea, haciendo concesiones que rompían algunas de las líneas rojas que ella misma se había trazado anteriormente y proponiendo incluir la posibilidad de que los diputados decidan sobre la convocatoria a un segundo referéndum, de que se establezca una unión aduanera temporal con sus socios europeos, de que se garanticen los derechos de los trabajadores; todas ellas propuestas presentadas por el opositor Partido Laborista durante semanas de negociaciones que terminaron fracasando. Ello provocó la renuncia de Andrea Leadsom, que era la representante del gobierno ante el Parlamento, y numerosos pedidos de renuncia a la Primera Ministra por parte de legisladores de su propio Partido Conservador.

En tanto, atento el compromiso adquirido por el gobierno británico ante las autoridades de la Unión Europea, el 23 de mayo se celebraron las elecciones para el Parlamento Europeo en el Reino Unido. Se impuso con el 30,5\% de los votos el Partido del Brexit, fundado por el populista Nigel Farage, que propone la salida inmediata del país del bloque regional. En segunda posición se colocó el Partido Liberal Demócrata, liderado por Vince Cable, que cosechó el $21,1 \%$ de los sufragios y que es contrario a la salida de Gran Bretaña de la Unión y propone la realización de un segundo referéndum. En tercer lugar se ubicó el Partido Laborista, que obtuvo el 15,2\% de las preferencias, habiendo sido castigado por la ambigüedad de su líder Jeremy Corbyn en torno al Brexit, dado que la mayoría de sus votantes desean que se celebre un segundo referéndum. El cuarto lugar fue para el Partido Verde, que logró el $12 \%$ de los votos y que también propone la realización de un nuevo referéndum; y el quinto lugar fue para el gobernante Partido Conservador, que solamente contó con el $9 \%$ de los apoyos y sufrió así una derrota histórica y humillante. Por su parte, los nacionalistas escoceses, que también desde el principio reclamaron una nueva consulta popular, se han visto recompensados con un apoyo mayoritario en su territorio. Como conclusión, se

\footnotetext{
${ }^{26} \mathrm{Al}$ respecto se debe recordar que el Parlamento británico rechazó en tres oportunidades el Acuerdo de salida que previamente había negociado el gobierno de Theresa May con la Unión Europea, lo hizo en sus sesiones del 15 de Enero y del 12 y 29 de Marzo.

27 Se llevaron a cabo entre el 23 y 26 de mayo de 2019.

${ }^{28}$ En dicha cumbre quien se mostró más reticente a conceder una nueva prórroga fue Francia, la que teme que se produzca una parálisis y bloqueo de las instituciones comunitarias si el Reino Unido continúa dentro de la Unión Europea.
} 
puede decir que las fuerzas políticas tradicionales (conservadores y laboristas) han sido los dos grandes perdedores de las elecciones europeas celebradas en el Reino Unido.

Ante dicha situación, el 24 de mayo de 2019, Theresa May anunció su renuncia al cargo de Primera Ministra, reconociendo su incapacidad para hacer aprobar al Parlamento el acuerdo que ella había negociado con Bruselas para retirar al Reino Unido de la Unión Europea y que fue rechazado por la Cámara de los Comunes en tres ocasiones.

La dimisión de May abrió un proceso de primarias dentro del Partido Conservador que concluyeron con el triunfo de Boris Johnson ${ }^{29}$, ex alcalde de Londres y Ministro de Relaciones Exteriores, y ferviente partidario de un Brexit duro, quien el 24 de julio se convirtió en el sucesor de Theresa May como Primer Ministro británico.

El 28 de agosto Boris Johnson solicitó y obtuvo de la reina Isabel II la orden de suspender la actividad del Parlamento entre el 10 de septiembre y el 14 de octubre ${ }^{30}$. Dicha maniobra política, que tenía por objeto el cierre de las Cámaras por un período más largo del habitual, fue ideada por el Primer Ministro para restar tiempo a la oposición para frenar un Brexit sin acuerdo, accionar que fue calificado por el Presidente de la Cámara de los Comunes, John Bercow, como un escándalo constitucional. El 24 de septiembre se expidió al respecto la Corte Suprema de Gran Bretaña, la cual falló que era una medida ilegal y dejó sin efecto el cierre del Parlamento británico, que comenzó a sesionar nuevamente al día siguiente.

El 17 de octubre el Reino Unido y la Unión Europea lograron alcanzar un nuevo acuerdo para la salida de Gran Bretaña del bloque regional europeo, el que alejaba temporalmente el temido Brexit brutal y retomaba básicamente el que había sido negociado por Theresa May, pero modificando su punto más conflictivo que era cómo garantizar un intercambio fluido de mercancías entre Irlanda del Norte (perteneciente al Reino Unido) y la República de Irlanda (país miembro de la Unión Europea) sin necesidad de reintroducir una frontera física ${ }^{31}$. Por su parte, el mismo 17 de octubre el Consejo Europeo aprobó el nuevo acuerdo de retirada del Reino Unido de la Unión Europea.

El 19 de octubre Boris Johnson se vio obligado a pedir a la Unión Europea un nuevo aplazamiento del Brexit, ya que el Parlamento británico aprobó una enmienda por la que el nuevo acuerdo cerrado con la Unión Europea no iba a ser adoptado hasta que se haya aprobado la legislación necesaria para implementarlo ${ }^{32}$. Esto hacía materialmente imposible que el Reino Unido pudiera materializar el Brexit el día 31 de octubre. En respuesta a dicha petición, la Unión Europea concedió a Gran Bretaña una nueva prórroga del plazo para que abandone la unión, fijándose como límite el 31 de enero de 2020, aunque podría retirarse antes de dicha fecha si el Parlamento británico completa con anterioridad el proceso de ratificación del nuevo acuerdo de salida.

\footnotetext{
${ }^{29}$ Votaron 92.000 afiliados de un total de casi 160.000 obteniendo Johnson el $66 \%$ de los votos frente al 34 $\%$ de su rival, Jeremy Hunt.

${ }^{30}$ El argumento que utilizó Johnson fue que el receso era necesario para preparar y presentar su programa de política nacional, que es una práctica habitual cuando hay cambio de gobierno aunque habitualmente sólo suele demandar una semana.

${ }^{31}$ Preservando de esta manera los Acuerdos de paz de Viernes Santo de 1998 que pusieron fin al conflicto irlandés.

32 Dicha medida activó automáticamente una ley que obliga al gobierno a pedir una nueva prórroga del Brexit.
} 
El 29 de octubre la Cámara de los Comunes decidió adelantar las elecciones generales del Reino Unido para el día 12 de diciembre de 2019, lo que las ha convirtido en un verdadero segundo referéndum de facto sobre la salida o permanencia de Gran Bretaña en la Unión Europea.

\section{Conclusiones finales: la insensatez del Brexit}

La "incomoda realidad" en que se ha convertido hoy día el Brexit tuvo su origen en un enorme acto de irresponsabilidad política por parte de ex Primer Ministro conservador David Cameron, quien -cuestionado por el ala dura de su partido y atemorizado por el incesante y rápido crecimiento del Partido de la Independencia del Reino Unido (UKIP) liderado por Nigel Farage- se comprometió y realizó un referéndum que nadie había pedido sobre la permanencia de Gran Bretaña en la Unión Europea, con la esperanza de ganarlo, debilitar por años al sector crítico de su agrupación política y retener a los votantes conservadores que estaban engrosando las filas del UKIP.

El Brexit se impuso luego de que sus impulsores realizaran una campaña donde abundaron las falsas promesas, alusiones al excepcionalismo británico, cargas de culpas de errores propios en Bruselas y nostálgicas ideas nacionalistas sobre un imperio que ya no existe, agitándose así los instintos xenófobos de una clase media inglesa de edad madura ${ }^{33}$ que se sentía amenazada y disminuida frente a los inmigrantes que provenían de otros países de Europa.

Indudablemente los ciudadanos británicos han cometido un grave error al votar a favor del Brexit, que -como se ha puntualizado-perjudica la economía y el comercio mundial, la imagen de la Unión Europea en el mundo y, principalmente en numerosos e importantes aspectos, el Reino Unido.

Las numerosas indefiniciones, dudas, prórrogas, marchas y contramarchas, fricciones y divisiones en los poderes gubernamentales y la sociedad británica con relación al Brexit no hacen más que poner en evidencia que ha sido un acto de gran insensatez que presenta un final totalmente abierto.

\section{Referencias bibliográficas:}

Arteaga, Félix (2016). "La defensa y seguridad de la UE tras el Brexit", ARI 51/2016, Real Instituto Elcano.

Baer, Jim (2017). "Brexit implications for Falkland/Malvinas dispute", Council on Hemispheric Affaris, Washington DC, 6 de febrero de 2017.

Eguidazu, Fernando (2019). "El Brexit, Gibraltar y España”, ARI 29/2019, Real Instituto Elcano.

\footnotetext{
${ }^{33}$ Los jóvenes británicos viajeros y cosmopolitas se han dado cuenta en los últimos años del error que cometieron al no concurrir a votar y reclaman ahora una segunda oportunidad de ir a las urnas para rectificar su error que ha hipotecado su futuro.
} 
López Basaguren, Alberto (2017). “Brexit: la secesión de la Unión Europea entre teoría y realidad”, Teoría y Realidad Constitucional, Núm. 40, UNED.

Mangas Martín, Araceli (2016). “¿Brexit? Escenarios Internacionales y Gibraltar”, Documento de Trabajo 9/2016, Real Instituto Elcano.

Revista Política Exterior, Especial junio 2016, "Reino Unido-UE, 23/06/2016".

Torrecuadrada García Lozano, Soledad y García Fuente, Pedro (2017). “¿Qué es el Brexit? Origen y posibles consecuencias", Anuario Mexicano de Derecho Internacional, Vol. XVII. 